\title{
Audit Sistem Informasi Akademik Universitas Telkom menggunakan Framework COBIT 5 Domain DSS untuk Optimasi Proses Service Delivery
}

\section{Telkom University Academic Information System Audit using COBIT 5 Framework Domain DSS for Optimization Service Delivery Process}

\author{
R. Wahjoe Witjaksono \\ Program Studi Sistem Informasi, Fakultas Rekayasa Industri, Universitas Telkom
}

INFO ARTIKEL

Article history:

Diterima 14-02-2019

Diperbaiki 21-04-2019

Disetujui 05-05-2019

Kata Kunci:

COBIT 5, Domain DSS,

Perguruan Tinggi, SIA

Keywords:

COBIT 5, Domain DSS,

Perguruan Tinggi, SIA
ABSTRAK

Pada awalnya teknologi informasi (TI) hanyalah sebagai pelengkap bisnis organisasi, seiring dengan kemajuan, teknologi informasi menjadi bagian yang sangat penting bagi operasional organisasi. Organisasi memanfaatkan teknologi informasi untuk mendukung tercapainya rencana strategis organisasi sesuai dengan visi dan misi organisasi tersebut. Seperti halnya organisasi besar lainnya, Universitas Telkom juga menginginkan teknologi informasi yang diterapkan selama ini dapat dimanfaatkan dengan baik dan sesuai dengan standar yang ditetapkan. Audit TI yang bertujuan untuk mengevaluasi dan memastikan pemenuhannya TI di suatu organisasi ditinjau dari pendekatan obyektif dari suatu standar. Audit diperlukan oleh Universitas Telkom untuk menilai kapabilitas, mengevaluasi, dan menghasilkan rekomendasi terhadap Sistem Informasi Akademik yang digunakan. COBIT 5 domain DSS (Deliver, Service, and Support) digunakan sebagai framework audit yang berfokus pada penilaian pengiriman, layanan teknologi informasi dan dukungannya untuk optimasi proses dan meningkatkan delivery service ke pengguna Sistem Informasi Akademik (SIA) di Universitas Telkom. Hasil dari penelitian ini adalah rekomendasi untuk meningkatkan level kapabilitas yang ingin dicapai berdasarkan dari level kapabilitas kondisi saat ini, kemudian dilakukan pengukuran keberhasilan proses berdasarkan metric COBIT 5.

\section{A B S T R A C T}

Recently, organizations or enterprise seen Information Technology (IT) as an important aspect to support business processes. It is seen as one of the key roles to improve efficiency of operational activities within the enterprise or organizations. Most of enterprise or organizations define Information Technology as tools to facilitate and support the achievement of strategic planning within enterprise, thus helps to achieve vision, mission and objective goals, the same goes with Telkom University. Despite the advantages brought by Information Technology, there is limited attention has been drawn by enterprise on the Information Technology governance, while this governance playing the biggest part on how the Information Technology helps every enterprise. There is a needs in term of governance on the Information Technology that has been implemented, thus the enterprise can gain the full benefit from it is implementation. To manage the information technology there is a needs on audit to helps evaluate and make sure the implementation based on certain standard. Information Technology in Telkom University needs audit to evaluate, asses the capabilities and define recommendation of information technology being used. COBIT 5 with DSS (Deliver, Service, dan Support) domains has been used in this research. The result of this research is recommendation to improve the level of capabilities target based on the level of capabilities existing. The measurement used to assess the successful based on COBIT 5 metric.

\section{Pendahuluan}

Pada awalnya teknologi informasi hanyalah sebagai pelengkap bisnis organisasi, seiring dengan kemajuan, teknologi informasi menjadi bagian yang sangat penting bagi operasional organisasi. Organisasi memanfaatkan TI sebagai suatu hal yang dapat digunakan untuk mendukung tercapainya 
rencana strategis organisasi dan berupaya menerapkan TI untuk mewujudkan visi, misi dan tujuannya secara efektif dan efisien dan mempunyai nilai kompetitif yang tinggi dalam menghadapi persaingan. Tata kelola teknologi informasi (IT governance) adalah bagian dari tata kelola organisasi yang mendalami sistem TI dan manajemen kinerja serta risikonya.

COBIT 5 dalam membantu organisasi untuk mencapai tujuan yang diinginkan dan memberikan nilai tambah melalui tata kelola TI dan manajemen organisasi yang efektif, mempunyai kerangka kerja yang komprehensif. Disamping itu untuk membantu organisasi dalam menciptakan nilai pemanfaatan IT yang optimal Cobit 5 bisa membantu dengan cara menjaga keseimbangan antara sumber daya, tingkat risiko, dan manfaat.

Dengan adanya penelitian ini, diharapkan dapat diketahui capability level dan kesenjangan (gap) sistem informasi yang digunakan di Universitas Telkom, sehingga pada akhirnya dapat memberikan rekomendasi perbaikan terkait dengan sistem informasi yang sudah dibangun dan langkah-langkah yang harus dilakukan untuk optimasi proses dan meningkatkan delivery service ke pengguna sistem informasi Akademik (SIA) di Universitas Telkom.

\section{Studi Literatur}

Audit adalah suatu proses yang sistematis dan objektif untuk memperoleh bukti-bukti dan mengevaluasinya tentang pernyataan tindakan dan transaksi yang bernilai ekonomi, dimana hal tersebut digunakan untuk memastikan tingkat kesesuaian pernyataan yang disampaikan dengan kriteriakriteria yang telah ditetapkan sebelumnya dan kemudian hasil-hasil yang didapat dikomunikasikan kepada pengunapengguna yang berkepentingan [1].

Audit Teknologi Informasi atau Sistem Informasi merupakan proses untuk mengumpulkan data-data dan mengevaluasi bukti-bukti yang diperoleh tersebut untuk menentukan apakah komputerisasi suatu sistem di suatu perusahaan atau organisasi itu sudah mempunyai ketetapan dan sudah menerapkan secara memadai sistem pengendalian internal dan melindungi semua aktiva dengan baik atau mengetahui aktiva yang telah disalahgunakan, menjamin integritas data, keandalan, efektifitas dan efesiensi dalam penyelenggaraan sistem informasi berbasis komputer [2].

\subsection{Tata Kelola}

Setiap organisasi harus menetapkan tata kelola yang baik agar bisa mencapai tujuan yang diharapkan. Sistem tata kelola organisasi yang baik, dibangun dan dijalankannya proses manajerial organisasi sesuai dengan prinsip-prinsip tata kelola, sehingga menjamin kelangsungan hidup organisasi secara terus menerus dan bermanfaat bagi stakeholdernya.

Tata kelola TI memerlukan keterlibatan dewan direksi dan eksekutif manajemen sebagai penanggung jawab tata kelola tersebut [3][4], pengelola TI [5][15] juga harus terlibat. Keterlibatan senior management adalah merancang hak pengambilan keputusan dan pertanggungjawaban terkait TI yang disesuaikan dengan perilaku penggunaan TI yang diharapkan. Jika perilaku yang diharapkan lingkupnya hanya pada unit bisnis, maka pengambilan keputusan terkait investasi TI ada pada kepala unit bisnis. Tetapi jika lingkupnya adalah seluruh organisasi maka keputusan terkait TI tersebut harus bersifat sentralisasi [6].

Mekanisme pengembangan tata kelola TI menggunakan perpaduan struktur, proses, dan mekanisme relasional. Struktur melibatkan adanya bagian-bagian atau fungsi-fungsi yang bertanggung jawab terhadap tata kelola TI seperti eksekutif TI dan IT committees. [7], [8]. Proses merujuk kepada pembuatan keputusan strategis dan monitoring melalui suatu framework misalnya IT balanced scorecard. Mekanisme relasional termasuk partisipasi pihak bisnis dan TI, dialog strategis, pembelajaran bersama, dan komunikasi yang baik [9]. Keterkaitan elemen tersebut membentuk kerangka kerja tata kelola TI sesuai dengan Gambar 1.

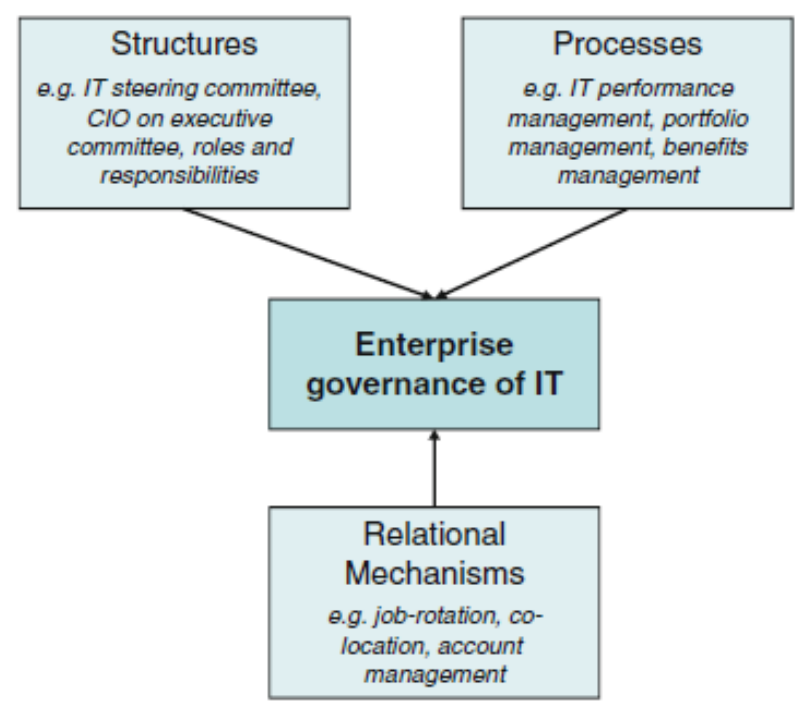

Gambar 1. Elemen Kerangka Kerja Tata Kelola TI [9]

\subsection{COBIT 5}

COBIT 5 merupakan kerangka yang membantu perguruan tinggi secara menyeluruh untuk mencapai tujuannya dalam mengelola tata kelola dan manajemen TI perguruan tinggi untuk menciptakan nilai yang optimal dari pemanfaatan TI secara menyeluruh dengan menjaga keseimbangan, mengoptimalkan tingkat resiko dan penggunaan sumber daya untuk mendapatkan keuntungan dalam pemanfaatan teknologi informasi yang meliputi seluruh ruang lingkup bisnis dan area fungsional, dengan mempertimbangkan kepentingan para stakeholder baik internal maupun eksternal.

COBIT 5 sudah memiliki model referensi proses yang detail, lengkap dan menyeluruh untuk menentukan dan menjelaskan mengenai proses tata kelola dan manajemen TI. Secara keseluruhan model referensi proses COBIT 5 terdapat 37 proses tata kelola dan manajemen, seperti terlihat pada gambar 2. Model referensi proses tersebut bisa mewakili semua proses yang biasa ditemukan di perguruan tinggi. Model referensi proses tersebut juga menyediakan model sebagai referensi yang mudah dipahami. Setiap perguruan tinggi harus bisa menentukan alur proses bisnisnya sendiri sesuai dengan kondisi yang dimiliki. 


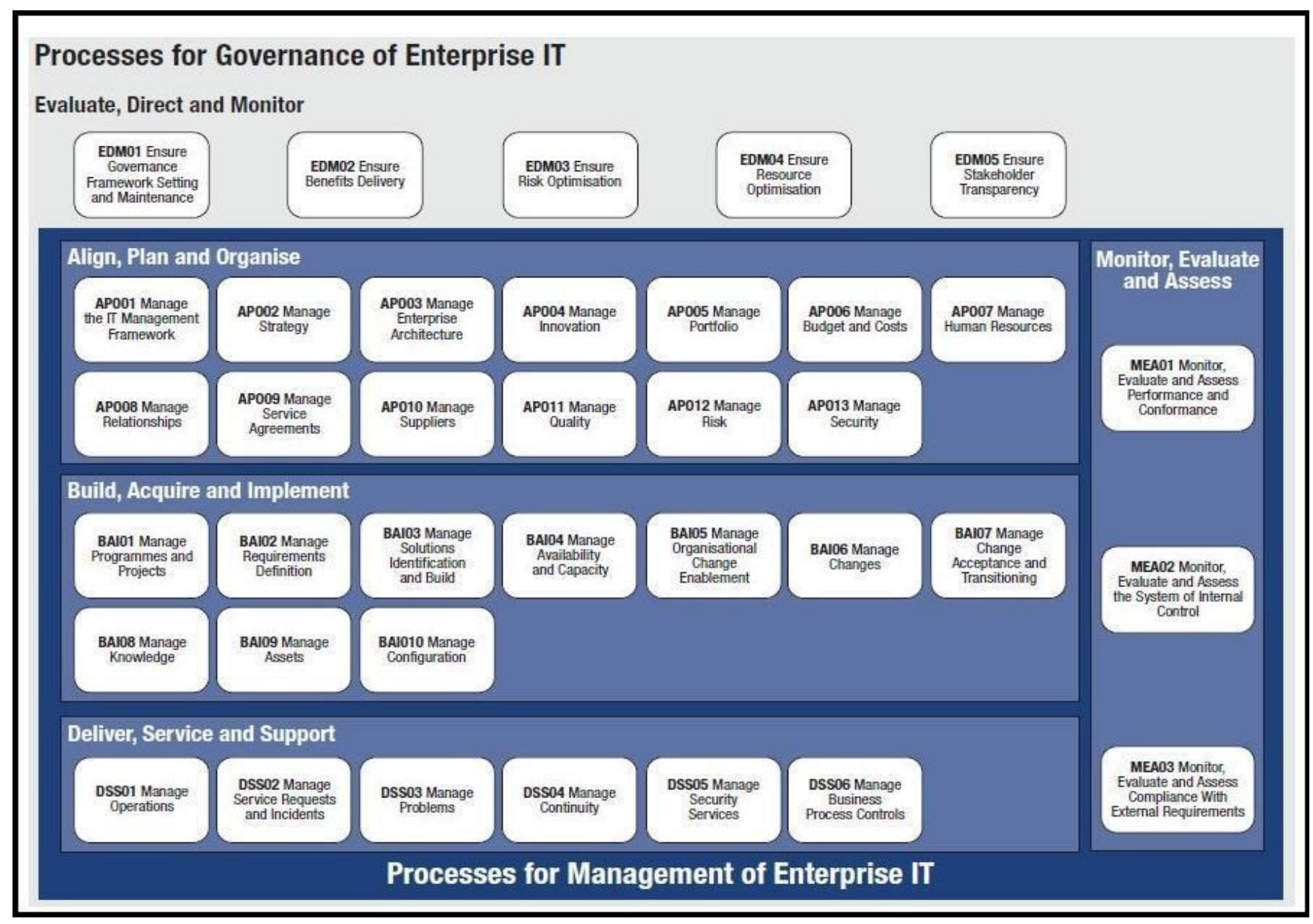

Gambar 2.

Model Referensi Proses dalam COBIT 5 [10]

Model referensi proses ini terbagi menjadi dua domain proses utama yaitu tata kelola dan manajemen. Tata kelola memiliki 5 (lima) proses, dimana didalam proses tata kelola ini ditentukan oleh praktik-praktik proses, yaitu proses Evaluate, Direct, dan Monitor atau disingkat EDM dalam setiap prosesnya. Manajemen memiliki 4 (empat) domain di area tanggung jawab. Keempat domain tersebut meliputi Plan, Build, Run, and Monitor (PBRM). Manajemen juga menyediakan ruang lingkup TI yang menyeluruh, yang terdiri dari Align, Plan, and Organize (APO), Build, Acquare, and Implement (BAI), Deliver, Service and Support (DSS), Monitor, Evaluate, and Assess (MEA).

Pembahasan kali ini hanya membahas Domain Deliver, Service and Support (DSS) dimana focus yang ditekankan lebih ke aspek penyampaian teknologi informasi terutama di Sistem Informasi Akademik Universitas Telkom. Hal ini dikarenakan Universitas Telkom telah mengimplementasikan hampir secara keseluruhan Sistem Informasi Akademik sehingga audit ini diperuntukkan untuk mengukur efisiensi dan efektifitas dari sistem informasi akademik dan nantinya akn mengeluarkan rekomendasi untuk optimasi proses service deliverynya.

Domain DSS meliputi bidang-bidang yang mengeksekusi aplikasi di dalam TI dan hasil-hasilnya, serta dukungan terhadap pelaksanaan TI agar lebih efektif dan efisien. Prosesproses di domain DSS terdiri dari DSS01 Manage Operations, DSS02 Manage Service Requests and Incidents, DSS03
Manage Problems, DSS04 Manage Continuity, DSS05 Manage Security Services, dan DSS06 Manage Business Process Controls.

\subsection{Indikator Assessment Kapabilitas Proses}

Dimensi kapabilitas yang digunakan untuk model penilaian proses mencakup enam tingkat kapabilitas dan didalamnya terdapat sembilan atribut proses. Menurut ISACA [10], assessment indikator kapabilitas proses terdiri dari 5 level, seperti terlihat pada tabel 1. Penilaian di setiap kapabilitas level [11-14], hasilnya diklasifikasikan dalam 4 kategori berikut:

1. $\mathrm{N}$ (Not achieved atau tidak tercapai) dengan nilai antara $0-15 \%$.

2. $\mathrm{P}$ (Partially achieved atau tercapai sebagian) nilai antara $15-50 \%$.

3. L (Largely achieved atau sebagian besar tercapai) dengan nilai antara $50-85 \%$.

4. F (Fully achieved atau tercapai penuh) dengan nilai antara $85-100 \%$.

\section{Metode Penelitian}

Penelitian terdiri dari beberapa tahapan yang runut, keluaran tahapan sebelumnya menjadi masukan tahapan berikutnya. Adapun tahapan-tahapan pada penelitian terlihat seperti pada gambar 3. Tahapan dimulai dengan merumuskan masalah, studi literature, pemilihan domain yang sesuai, 
dalam pemilihan domain ini dipilih domain DSS karena SIA Universitas Telkom sudah berjalan dengan baik namun masih terdapat sedikit keluhan di kalangan pengguna. Kemudian dilanjutkan pengumpulan data yang mendukung domain DSS, tahap berikutnya adalah analisis, pembuatan ukuran keberhasilan proses dan tahap terakhir adalah pemberian rekomendasi untuk meningkatkan proses pelayanan dan penyampaian SIA Universitas Telkom kepada pengguna.

Tabel 1.

Level Proses

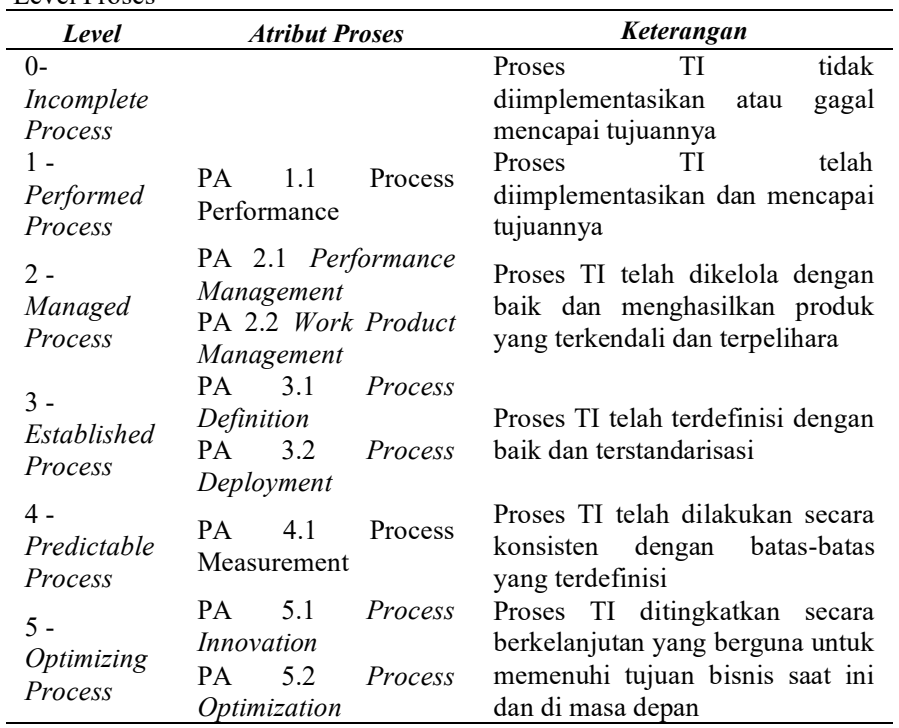

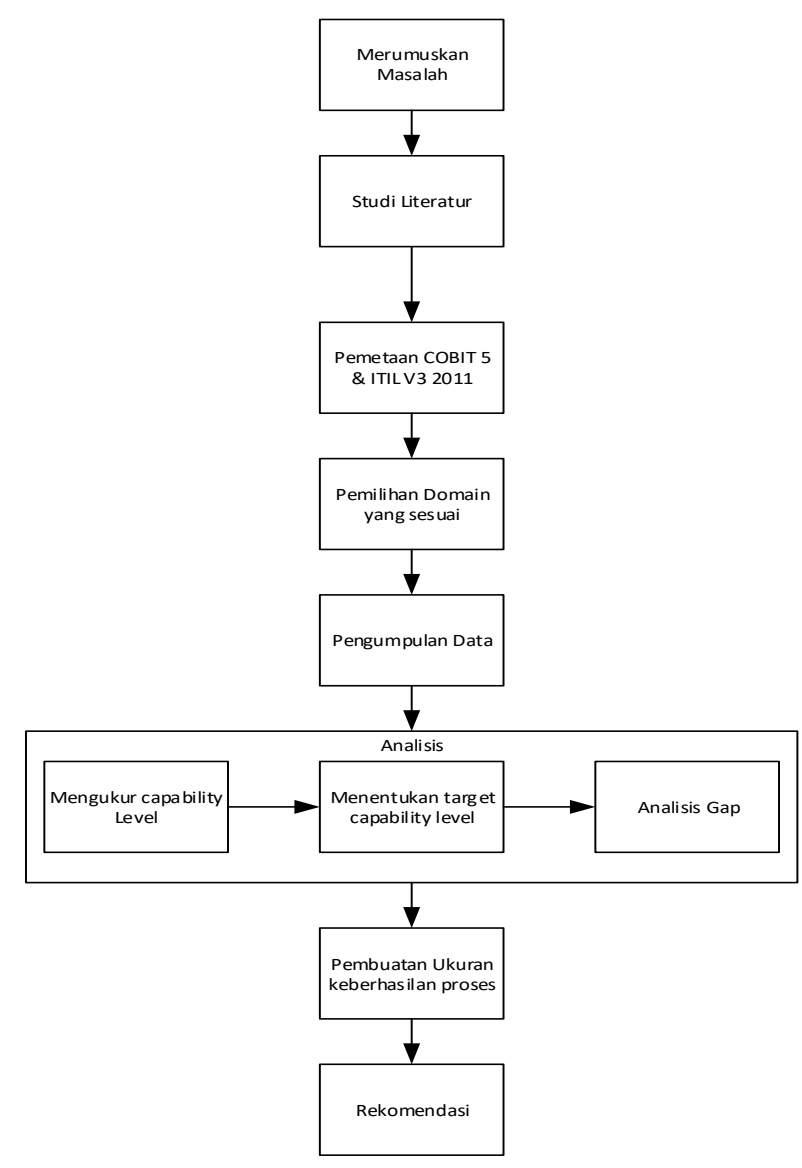

Gambar 3. Sistematika Penelitian

\section{Hasil dan Pembahasan}

\subsection{Penilaian Kapabilitas Level}

Tujuan penelitian ini yaitu pembuatan kerangka kerja evaluasi Sistem Informasi Akademik Universitas Telkom. Pembuatan kerangka kerja berkaitan dengan penerapan ini dimulai dengan penjelasan kondisi dari masing-masing proses COBIT 5. Setelah mendapatkan penjelasan dari masingmasing atribut kemudian langkah yang dilakukan adalah menganalisa dengan membandingkan atribut COBIT 5 dengan kondisi aktual yang terjadi di SIA Universitas Telkom.

Proses pengambilan data aktual dilakukan diskusi dan wawancara ke pegawai di Direktorat SISFO. Wawancara dilakukan dengan menerapkan masing-masing kriteria tiap atribut dan melakukan penilaian kapabilitas level tiap prosesproses TI di COBIT 5.

Penentuan Level ditiap aktifitas ini dilakukan dengan memilih nilai yang paling banyak muncul (modus) pada tiap aktifitasnya, dan jika nilai yang muncul pada Level yang dipilih ada nilai yang sama sebanyak 2 atau mungkin lebih, maka yang di pilih adalah nilai Level yang terkecil diantaranya, misalkan pada DSS02.01 pada aktifitas ke 1 terdapat 7 responden, kemudian dari 7 responden yang memilih di Level 3 adalah 2 orang, di Level 4 adalah 3 orang, dan di Level 5 adalah 2 orang. Maka Level yang terpilih adalah pada Level 4, karena bisa diartikan 2 responden yang memilih di Level 5 tersebut juga berpikir bahwa pada level ke 5 telah berada pada Level 4.

\subsection{Analisis Hasil Kuesioner}

Setelah dilakukan analisis hasil kuisioner maka didapatkanlah hasil berupa nilai-nilai dari tiap-tiap aktifitas yang terdapat pada domain DSS dan dimasukan ke dalam form kerja audit. Tindakan selanjutnya yang dilakukan adalah mencari nilai yang paling banyak muncul di tiap proses untuk bisa mengetahui kondisi tiap proses yang ada dengan melihat nilai yang paling banyak muncul dari seluruh level yang dipilih dari setiap item pertanyaan di tiap domain. Hasil dari proses analisis ini adalah saran perbaikan yang perlu dilakukan oleh Direktorat SISFO terhadap SIA dengan mengacu pada atribut COBIT tersebut.

\subsection{Pengumpulan Bukti dan Kondisi Saat Ini}

Dalam penentuan suatu kondisi yang di dapat sudah valid akan diperkuat lagi dengan melakukan pengumpulan bukt-bukti yang sudah ditetapkan pada COBIT 5 Domain DSS. Bukti yang berhasil di dapat akan diperiksa dengan membandingkan kesesuaiaan kondisi saat ini yang telah diperoleh dan menjadi alat ukur tersendiri.

Dari data tersebut terdapat beberapa bukti yang diperoleh dan ada yang tidak diperoleh dan juga pendeskripsian yang menerangkan kondisi dari bukti yang dicari, hal tersebut dapat dijadikan sebagai evaluasi terhadap tingkat kapabilitas yang di dapat. Dari pengumpulan bukti bisa diketahui kondisi saat ini untuk sistem informasi akademik di Universitas Telkom.

Data tersebut kemudian diolah untuk diketahui level yang dicapai pada kondisi saat ini dengan menggunakan kapabilitas level. Dari kapabilitas level yang didapat dan untuk memudahkan dalam mencari kondisi terkini berdasarkan kriteria kapabilitas level yang telah ditetapkan maka nilai-nilai 
yang diperoleh tadi dibulatkan. Gap pengelolaan layanan TI didapatkan melalui perbandingan antara tingkat kapabilitas di Direktorat SISFO, Universitas Telkom pada kondisi as-is dengan tingkat kapabilitas pada kondisi to-be. Jika ditulis dalam bentuk tabel, maka gap kapabilitas level proses layanan TI seperti terlihat pada tabel 2. Untuk mengetahui kesenjangan antara kondisi target dan kondisi saat ini digunakan gap analysis. Gambar 4 terlihat dengan jelas kesenjangan setiap proses.

Berdasarkan data terlihat bahwa kondisi level saat ini dibandingkan dengan kondisi level yang ingin dicapai, gapnya tidak terlalu besar, 3 proses yaitu proses DSS01, DSS05, DSS06 mempunyai kesenjangan 0 dan 3 proses lainnya yaitu DSS02, DSS03, dan DSS04 mempunyai kesenjangan 1. Dari data tersebut dapat diketahui proses-proses mana yang harus dilakukan perbaikan terlebih dulu, yaitu proses-proses yang mempunyai nilai gap lebih besar sama dengan 1 yaitu proses DSS02,DSS03, dan DSS04. Sedangkan proses lainnya belum menjadi prioritas perbaikan.

Tabel 2

Gap Kapabilitas Proses-Proses TI dengan Target Kapabilitas di Direktorat SISFO

\begin{tabular}{|c|c|c|c|}
\hline Proses/Aktifitas & $\begin{array}{l}\text { Level } \\
\text { Target }\end{array}$ & $\begin{array}{c}\text { Level } \\
\text { saat } \\
\text { ini }\end{array}$ & Gap \\
\hline DSS01 - Manage Operations & 4 & 4 & $\mathbf{0}$ \\
\hline $\begin{array}{l}\text { DSS01.01 Menjalankan Prosedur } \\
\text { Operasional }\end{array}$ & 4 & 4 & \\
\hline $\begin{array}{l}\text { DSS01.02 Mengelola Layanan } \\
\text { Outsourced IT }\end{array}$ & 5 & 5 & \\
\hline DSS01.03 Memonitor Infrastruktur TI & 5 & 5 & \\
\hline DSS01.04 Mengelola Lingkungan & 4 & 4 & \\
\hline DSS01.05 Mengelola Fasilitas & 4 & 4 & \\
\hline $\begin{array}{l}\text { DSS02 - Manage Service Requests } \\
\text { and Incidents }\end{array}$ & 5 & 4 & 1 \\
\hline $\begin{array}{l}\text { DSS.02.01 Mendefinisikan Skema } \\
\text { Klasifikasi Insiden dan Permintaan } \\
\text { Layanan }\end{array}$ & 4 & 4 & \\
\hline $\begin{array}{l}\text { DSS.02.02 Mengklasifikasikan dan } \\
\text { memprioritaskan permintaan dan } \\
\text { insiden }\end{array}$ & 5 & 4 & \\
\hline $\begin{array}{l}\text { DSS.02.03 Memverifikasi, } \\
\text { menyetujui dan memenuhi permintaan }\end{array}$ & 5 & 4 & \\
\hline $\begin{array}{l}\text { DSS.02.04 Mendiagnosis dan } \\
\text { mengalokasikan insiden }\end{array}$ & 5 & 4 & \\
\hline $\begin{array}{l}\text { DSS02.05 Menyelesaikan dan } \\
\text { memulihkan insiden }\end{array}$ & 5 & 4 & \\
\hline $\begin{array}{l}\text { DSS02.06 Menutup permintaan } \\
\text { layanan dan insiden }\end{array}$ & 4 & 4 & \\
\hline $\begin{array}{l}\text { DSS02.07 Melacak status dan } \\
\text { membuat laporan }\end{array}$ & 4 & 4 & \\
\hline DSS03 - Manage Problems & 4 & 3 & 1 \\
\hline $\begin{array}{l}\text { DSS03.01 Mengidentifikasi dan } \\
\text { mengklasifikasikan masalah }\end{array}$ & 4 & 3 & \\
\hline $\begin{array}{l}\text { DSS03.02 Menginvestigasi dan } \\
\text { mendiagnosis masalah }\end{array}$ & 4 & 3 & \\
\hline $\begin{array}{l}\text { DSS03.03 Mencatat kesalahan yang } \\
\text { diketahui }\end{array}$ & 4 & 3 & \\
\hline $\begin{array}{l}\text { DSS03.04 Mengatasi dan menutup } \\
\text { masalah }\end{array}$ & 4 & 3 & \\
\hline $\begin{array}{l}\text { DSS.03.05 Menjalankan manajemen } \\
\text { masalah secara proaktif }\end{array}$ & 3 & 3 & \\
\hline
\end{tabular}

Tabel 2 (Lanjutan)

Gap Kapabilitas Proses-Proses TI dengan Target Kapabilitas di Direktorat SISFO

\begin{tabular}{|c|c|c|c|}
\hline Proses/Aktifitas & $\begin{array}{l}\text { Level } \\
\text { Target }\end{array}$ & $\begin{array}{c}\text { Level } \\
\text { saat } \\
\text { ini }\end{array}$ & Gap \\
\hline DSS04 - Manage Continuity & 5 & 4 & 1 \\
\hline $\begin{array}{l}\text { DSS04.01 Mendefinisikan kebijakan } \\
\text { keberlangsungan bisnis, obyektif dan } \\
\text { caupan }\end{array}$ & 5 & 4 & \\
\hline $\begin{array}{lll}\text { DSS04.02 } & \text { Menjaga } & \text { strategi } \\
\text { keberlanjutan } & & \end{array}$ & 5 & 4 & \\
\hline $\begin{array}{lll}\text { DSS04.03 Mengembangkan } & \text { dan } \\
\text { mengimplementasikan respon } & \text { dari } \\
\text { keberlangsungan bisnis } & & \end{array}$ & 5 & 4 & \\
\hline $\begin{array}{l}\text { DSS04.04 Latihan, tes, dan review } \\
\text { dokumen rencana kelanjutan } \\
\text { bisnis/business continuity plan (BCP) }\end{array}$ & 5 & 4 & \\
\hline $\begin{array}{l}\text { DSS04.05 Review, mempertahankan, } \\
\text { dan meningkatkan rencana } \\
\text { kesinambungan }\end{array}$ & 4 & 4 & \\
\hline $\begin{array}{l}\text { DSS04.06 Mengadakan training } \\
\text { untuk rencana kesinambungan }\end{array}$ & 4 & 4 & \\
\hline DSS04.07 Mengatur backup & 5 & 4 & \\
\hline DSS04.08 Melakukan review ulang & 5 & 4 & \\
\hline DSS05 - Manage Security Services & 5 & 5 & $\mathbf{0}$ \\
\hline DSS05.01 Melindungi dari malware & 5 & 5 & \\
\hline $\begin{array}{l}\text { DSS05.02 Mengelola jaringan dan } \\
\text { keamanan konektivitas }\end{array}$ & 4 & 4 & \\
\hline $\begin{array}{l}\text { DSS05.03 Mengelola keamanan } \\
\text { titikakhir }\end{array}$ & 5 & 5 & \\
\hline $\begin{array}{lcl}\text { DSS05.04 Mengelola } & \text { identitas } \\
\text { pengguna dan akses logika } & \end{array}$ & 5 & 5 & \\
\hline $\begin{array}{l}\text { DSS05.05 Mengelola akses fisik } \\
\text { untuk aset TI }\end{array}$ & 5 & 5 & \\
\hline $\begin{array}{l}\text { DSS05.06 Mengelola dokumen } \\
\text { sensitif dan perangkat keluaran }\end{array}$ & 5 & 5 & \\
\hline $\begin{array}{l}\text { DSS05.07 Memantau infrastruktur } \\
\text { yang terkait dengan kejadian } \\
\text { keamanan }\end{array}$ & 4 & 4 & \\
\hline $\begin{array}{l}\text { DSS06 - Manage Business Process } \\
\text { Controls }\end{array}$ & 4 & 4 & O \\
\hline $\begin{array}{l}\text { DSS06.01 Menyelaraskan kegiatan } \\
\text { kontrol yang terdapat di proses bisnis } \\
\text { dengan perusahaan }\end{array}$ & 5 & 5 & \\
\hline $\begin{array}{l}\text { DSS06.02 Mengontrol pemrosesan } \\
\text { informasi }\end{array}$ & 5 & 5 & \\
\hline $\begin{array}{l}\text { DSS06.03 Mengelola peran, tanggung } \\
\text { jawab, hak akses dan tingkat otoritas }\end{array}$ & 4 & 4 & \\
\hline $\begin{array}{l}\text { DSS06.04 Mengelola kesalahan dan } \\
\text { pengecualian }\end{array}$ & 5 & 4 & \\
\hline $\begin{array}{l}\text { DSS06.05 Memastikan penelusuran } \\
\text { informasi dan akuntabilitas }\end{array}$ & 4 & 4 & \\
\hline $\begin{array}{l}\text { DSS06.06 Mengamankan } \\
\text { informasi }\end{array}$ & 4 & 4 & \\
\hline
\end{tabular}

\subsection{Rekomendasi}

Rekomendasi diberikan kepada domain yang terdapat gap, yaitu Domain DSS02, DSS03, dan DSS04. Penentuan prioritas proses-proses TI berdasarkan COBIT 5 dengan cara meningkatkan kapabilitas level proses-proses TI tersebut. Untuk level 3, akan ditingkatkan ke level 4 dan kapabilitas level yang telah mencapai level 4 dapat ditingkatkan menjadi level 5. Rekomendasi yang diberikan untuk meningkatkan kualitas Sistem Informasi Akademik. 


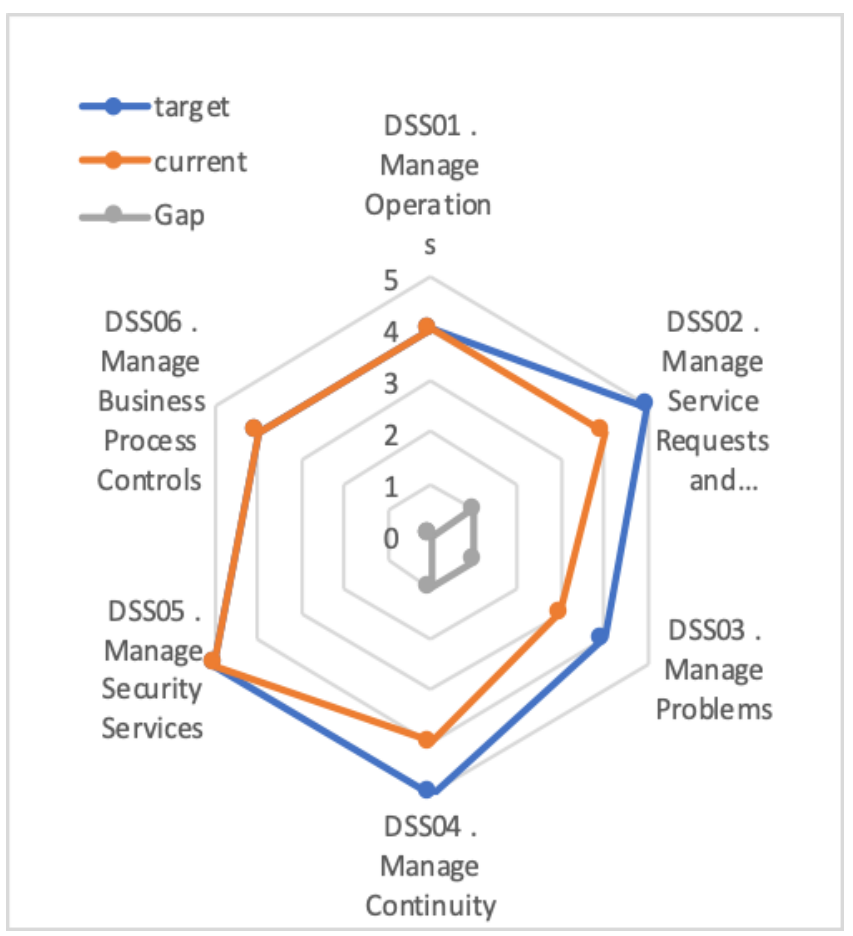

Gambar 3.

Radar Chart Tingkat Kapabilitas Current vs Target

\subsubsection{Rekomendasi DSSO2}

Rekomendasi untuk DSS02 adalah sebagai berikut:

1. Mengoptimasi fungsi Helpdesk dari user, terutama untuk mempersingkat waktu dalam pelaporan insiden dengan mengidentifikasi, mencatat dan mengklafisikan tingkatan insiden, terutama untuk insiden yang berpengaruh terhadap keamanan SIA yang dilaporkan oleh user, supaya bisa dibuatkan mitigasi dan model pencegahan terhadap potensi insiden yang kemungkinan terjadi dan memprioritaskan sesuai dengan tingkat kekritisan yang mempengaruhi bisnis dan perjanjian layanan dengan bantuan sistem berdasarkan kejadian-kejadian sebelumnya.

2. Memverifikasi prosedur permintaan layanan dengan memenuhinya sesuai dengan kriteria yang ditentukan untuk permintaan pelayanan yang disetujui. Dengan meningkatkan SLA dan selalu berinovasi untuk menentukan standar standar layanan yang sering diminta atau memenuhi standar yang disepakati. Dan terus melakukan inovasi dan optimasi secara berkala.

3. Membuat inovasi strategi dalam menginvestigasi, mendiagnosa dan mengalokasikan terhadap insiden yang belum terselesaikan, menganalisis dan mengevaluasi kembali inovasi strategi yang dibuat untuk mengetahui dan menentukan kemungkinan penyebabnya dan mengalokasikan untuk penyelesainnya, dan selalu melakukan inovasi dan optimasi.

4. Mendokumentasikan, menerapkan, dan menguji solusi atau solusi yang diidentifikasi dan melakukan tindakan pemulihan untuk memulihkan layanan terkait TI dengan selalu berinovasi dan optimasi agar dokumentasi resolusi insiden dan penilaian tersebut dapat digunakan sebagai sumber pengetahuan di masa depan

\subsubsection{Rekomendasi DSSO3}

Rekomendasi untuk DSS03 adalah sebagai berikut:

1. Membuat prosedur atau fungsi yang bisa digunakan untuk mengetahui masalah atau insiden yang terjadi secara cepat dan tepat sasaran.

2. Menentukan penyelesaian yang tepat dan semestinya terhadap akar permasalahan yang telah diketahui dan dianalisis.

3. Memantau kinerja bagian terkait dalam menyelesaikan masalah yang menjadi tanggung jawabnya.

4. Membuat dokumentasi dan menganalisa kembali laporanlaporan terhadap masalah yang ada, kemudian menganalisa akar-akar permasalahan yang muncul dan cara memecahkan masalah tersebut, agar masalah yang sama tidak terjadi lagi.

5. Membuat sistem atau SOP (Standar Operation Procedure) tata cara menyelesaikan masalah, dan prosedur tersebut bisa dipantau oleh pihak yang berkepentingan.

6. Menganalisa sumberdaya yang digunakan untuk mengoptimalkan sumberdaya yang dimiliki dalam memecahkan permasalahan yang ada.

\subsubsection{Rekomendasi DSS04}

Rekomendasi untuk DSS04 adalah sebagai berikut:

1. Rapat budget perlu dilakukan secara rutin dan konsisten untuk mengontrol, mengevaluasi, dan membuat proyeksi, agar selalu dapat dilakukan perbaikan-perbaikan sehingga target rencana strategis 5 tahun yang sudah ditetapkan dapat tercapai.

2. Memastikan pelaksanaan backup dan restore data telah dilakukan, serta reliability dan availibility data telah terpenuhi sesuai SOP yang telah ditetapkan dan dilakukan monitoring terhadap kegiatan tersebut serta selalu mengevaluasinya.

3. Pelatihan mengenai proses bisnis SIA bagi Dosen, mahasiswa baru, dan karyawan yang berkepentingan perlu diadakan rutin, minimum 1 tahun 1 kali, yang berguna untuk memahami dan meningkatkan pengetahuan karyawan.

4. Mengukur keberlangsungan proses SIA untuk mengetahui tingkat kematangan dan kesenjangan proses tersebut, kemudian mendokumentasikannya dan melakukan evaluasi.

5. Menetapkan ukuran untuk pengembangan pelatihan sumberdaya manusia yang dimiliki, dan memantau keberlangsungannya

6. Memastikan keamanan terhadap distribusi data yang bersifat rahasia.

7. Membuat sistem yang mampu merespon terhadap insiden dan mengkomunikasikannya, mendokumentasikan dan selalu dievaluasi.

\subsubsection{Rekomendasi keseluruhan proses}

Kapabilitas Level yang didapat secara keseluruhan adalah Level 4 Predictable Process, sehingga rekomendasi yang disusun adalah:

1. Membuat aturan kinerja untuk mengukur layanan yang harus dipenuhi dalam setiap proses bisnis, agar proses SIA dapat berjalan sesuai dengan target yang ditetapkan. 
2. Membuat sistem atau SOP untuk memonitoring dan mengevaluasi proses bisnis SIA yang tepat yang berfungsi untuk mengoptimalkan keberlanjutan SIA.

3. Membuat pembaruan-pembaruan proses bisnis SIA sehingga bisa semakin efisien dan efektif dan berjalan ke arah yang lebih baik.

4. Terhadap target pencapaian rencana strategis 5 tahunan, meningkatan pengawasan, kontrol, dan selalu melakukan evaluasi per tri wulan, per semester dan per tahun terhadap proses bisnis SIA.

5. Berdasarkan prioritas, maka domain yang harus dilaksanakan terlebih dahulu berdasarkan rekomendasi adalah domain-domain DSS02, DSS03, dan DSS04. Hal ini dilakukan setidaknya untuk menghilangkan gap dan kemudian dilanjutkan untuk meningkatkan performansi dalam berlangsungnya bisnis proses.

\subsection{Pembuatan dan Rekomendasi Pengukuran Keberhasilan Proses-Proses TI COBIT 5}

Proses perancangan kerangka kerja sebagian besar sudah dilakukan sebelumnya. Oleh karena itu, langkah selanjutnya adalah menentukan pengukuran keberhasilan proses yang bisa diukur dari metrik process goals pada tiap proses TI yang diperoleh dari COBIT 5. Metrik ini diperoleh dari 6 (enam) proses-proses TI di COBIT 5 pada hasil pemetaan sebelumnya. Metrik ini diturunkan dari metrik process goals dalam proses-proses TI di COBIT 5. Berdasarkan daftar Metrik dari Process Goal dalam COBIT 5 atas tiap prosesproses TI tersebut, maka ditentukan rekomendasi KPI yang dapat diimplementasikan oleh Direktorat SISFO dalam rangka perbaikan layanan SIA di Universitas Telkom. Rekomendasi pengukuran keberhasilan proses berdasarkan related metrics terdapat pada tabel 3, dengan skala pengukuran berupa angka, waktu, persen, atau ordinal dengan target minimal atau maksimal sesuai dengan ukuran yang ingin dicapai.

\section{Kesimpulan}

Berdasarkan audit yang dilakukan pada Direktorat SISFO Universitas Telkom dalam studi kasus sistem informasi akademik (SIA) dengan framework COBIT 5 Domain DSS (Deliver, Service, and Support) maka dapat ditarik kesimpulan:

Sistem informasi akademik di Universitas Telkom sudah berjalan dengan baik dan jika dikaitkan dengan COBIT 5 domain DSS sudah mencapai level capability di level 3 sampai level 4, bahkan ada beberapa yang sudah mencapai level 5.

Rekomendasi yang harus dipenuhi oleh Universitas Telkom dalam ini Direktorat SISFO untuk meningkatkan sesuai dengan level yang ingin dicapai adalah:

Dengan dilakukan audit dapat diketahui adanya 1 proses yang mempunyai kapabilitas level 5 yaitu DSS05, 4 proses yang mempunyai kapabilitas level 4 yaitu DSS01, DSS03, DSS04, DSS05 dan DSS06, serta 1 proses yang mempunyai kapabilitas level 3 yaitu proses DSS03.

Menurut kapabilitas level masing-masing proses setelah dianalisa maka ditentukan level target yang akan dicapai 1 level di atas kapabilitas level yang ditentukan, sehingga didapat level target berada di tingkat 5 untuk DSS01, DSS02, DSS04, DSS05, DSS06, dan tingkat 4 untuk DSS03. Tingkat capability keseluruhan berdasarkan keseluruhan rata-rata adalah berada di level 4, yang berarti sebagian besar aktifitas pada domain DSS untuk Sistem Informasi Akademik Universitas Telkom telah dilakukan dengan baik, ada standar kontrol dan standar pengukuran yang sudah berjalan dengan baik. Untuk optimasi proses maka harus dilakukan perbaikanperbaikan proses dan pencapaian tujuan proses, dengan cara melakukan semua aktifitas pada process practice yang telah direkomendasikan oleh COBIT 5.

Tabel 3

Rekomendasi Keberhasilan Pengukuran Proses

\begin{tabular}{|c|c|c|c|}
\hline $\begin{array}{c}\text { Proses } \\
\text { COBIT } 5\end{array}$ & Related Metrics & Skala & Target \\
\hline $\begin{array}{l}\text { DSSO1 } \\
\text { manage } \\
\text { operations }\end{array}$ & $\begin{array}{l}\text { Jumlah eksekusi diluar SOP } \\
\text { Jumlah kejadian yang disebabkan } \\
\text { masalah operasional } \\
\text { Rasio terhadap jumlah kejadian }\end{array}$ & Angka & Minimal \\
\hline $\begin{array}{l}\text { DSSO2 } \\
\text { manage } \\
\text { service } \\
\text { request } \\
\text { and } \\
\text { incidents }\end{array}$ & $\begin{array}{l}\text { Jumlah dan persentase kejadian } \\
\text { mengganggu proses bisnis yang } \\
\text { kritikal } \\
\text { Waktu rata-rata kejadian terhadap } \\
\text { layanan berbasis TI } \\
\text { Persentase insiden yang dapat } \\
\text { diselesaikan dengan periode } \\
\text { waktu yang disepakati. } \\
\text { Tingkat kepuasan user terhadap } \\
\text { service request fulfillment. }\end{array}$ & $\begin{array}{l}\text { Angka } \\
\text { Angka } \\
\text { dan } \\
\text { Persen }\end{array}$ & $\begin{array}{l}\text { Minimal } \\
\text { Minimal }\end{array}$ \\
\hline $\begin{array}{l}\text { DSSO3 } \\
\text { manage } \\
\text { problems }\end{array}$ & $\begin{array}{l}\text { Persentase log problem sebagai } \\
\text { bagian dari kegiatan manajemen } \\
\text { problem secara proaktif }\end{array}$ & $\begin{array}{l}\text { Ordinal } \\
\text { Persen }\end{array}$ & $\begin{array}{l}\text { Maksimal } \\
\text { Maksimal }\end{array}$ \\
\hline $\begin{array}{l}\text { DSSO4 } \\
\text { manage } \\
\text { continuity }\end{array}$ & $\begin{array}{l}\text { Persentase keberhasilan dan tepat } \\
\text { waktu restoration back up dan } \\
\text { alternatif jumlah penggandaan } \\
\text { media } \\
\text { Persentase back up yang } \\
\text { disimpan secara aman } \\
\text { Jumlah pelatihan yang telah } \\
\text { mencapai tujuan recovery } \\
\text { Frekuensi pengujian } \\
\text { Persentase stakeholder internal } \\
\text { dan eksternal yang telah } \\
\text { menerima pelatihan. }\end{array}$ & $\begin{array}{l}\text { Persen } \\
\text { Angka }\end{array}$ & $\begin{array}{l}\text { Maksimal } \\
\text { Maksimal }\end{array}$ \\
\hline $\begin{array}{l}\text { DSSO5 } \\
\text { Manage }\end{array}$ & $\begin{array}{l}\text { Jumlah kerawanan } \quad \text { yang } \\
\text { ditemukan }\end{array}$ & Angka & Minimal \\
\hline $\begin{array}{l}\text { Security } \\
\text { Services }\end{array}$ & $\begin{array}{l}\text { Jumlah cabang firewall } \\
\text { Persentase individu yang } \\
\text { menerima pelatihan tentang } \\
\text { kesadaran dalam penggunaan } \\
\text { endpoint devices } \\
\text { Jumlah insiden yang berkaitan } \\
\text { dengan endpoint devices } \\
\text { Jumlah insiden yang berhubungan } \\
\text { dengan akses yang tidak memiliki } \\
\text { otorisasi terhadap informasi }\end{array}$ & $\begin{array}{l}\text { Angka } \\
\text { Persen }\end{array}$ & $\begin{array}{l}\text { Maksimal } \\
\text { Maksimal }\end{array}$ \\
\hline $\begin{array}{l}\text { DSS 06 } \\
\text { Manage } \\
\text { business } \\
\text { controls }\end{array}$ & $\begin{array}{l}\text { Jumlah insiden dan laporan audit } \\
\text { penemuan indikasi kegagalan key } \\
\text { control } \\
\text { Persentase ketidaklengkapan log } \\
\text { transaksi yang tercatat } \\
\text { Jumlah insiden dimana history } \\
\text { transaksi tidak dapat diperbaiki }\end{array}$ & Angka & Minimal \\
\hline & & Angka & Minimal \\
\hline
\end{tabular}




\section{Referensi}

[1] ISACA, 2012, COBIT 5 A Business Framework for the Governance and Management of Enterprise. IL, USA.

[2] Ron Weber,1999, Information System Control and Audit. Prentice-Hall, Inc: New Jersey.

[3] ITGI, 2007, COBIT 4.1. www.itgi.org.

[4] ITGI, ISACA, OGC, dan TSO, 2008, Aligning COBIT 4.1, ITIL V3, and ISO/IEC 27002 for Business Benefit. England and United State of America.

[5] W.Van Gembergen, 2003, Strategies for Information Technology Governance, Hershey, PA: Idea Group Publishing.

[6] Weill, Peter dan Ross. Jeanne W, 2004, IT Governance; How Top Performers Manage IT Decision Rights for Superior Results, Harvard Business School Press, Boston.

[7] R. Peterson, 2004, Information Strategies and Tacties for Information Technology

[8] Van Grembergen, W., De Haes, S. and Guldentops, E. (2004) Structures, Processes and Relational Mechanisms for IT Governance. In: Van Grembergen, W., Ed., Strategies for Information Technology Governance, Idea Group Publishing, Belgium, 1-37.

[9] De Haes, Steven. Wim Van Grembergen, 2015, Enterprise Governance of Information Technology Achieving Alignment and Value, Featuring COBIT 5 Second Edition, Springer International Publishing, Switzerland

[10] ISACA, 2013, COBIT Process Assessment Model (PAM):Using COBIT 5. Rolling Meadows, IL, USA.

[11] ISACA, 2012, COBIT 5: Enabling Process. Rolling Meadows, IL, USA.

[12] ISACA, 2013, COBIT Process Assessment Model (PAM):Using COBIT 5. Rolling Meadows, IL, USA.

[13] ISACA, 2013, COBIT Self Assessment Guide: Using COBIT 5. Rolling Meadows, IL, USA.

[14] Mallete, Debra, 2012, October, COBIT 5 Process Assessment Method (PAM). Paper presented at 2012 SF ISACA Fall Conference, San Fransisco, CA.

[15] V. R. Andwika, R. W. Witjaksono, and A. H. Azizah, "Analysis of User Acceptance of ERP System on After Sales Function Using Unified Theory of Acceptance and Use of Technology (UTAUT) Model," Int. J. Adv. Data Inf. Syst., vol. 1, no. 1, pp. 26-33, Apr. 2020. 